\title{
Imagen del mes: Hipoalbuminemia e infecciones respiratorias a repetición; el diagnóstico puede estar al alcance del colonoscopio
}

\author{
Luis Antonio Díaz P. ${ }^{1}$, Luis Rojas O. ${ }^{2}$ y Manuel Álvarez L. ${ }^{1}$
}

Image of the month: Hypoalbuminemia and recurrent respiratory infections:

Diagnosis can be reached with the colonoscope.

\section{Caso clínico}

Se presenta el caso de una paciente de 28 años, sexo femenino, con antecedentes de un síndrome edematoso desde la infancia, asociado a hipogammaglobulinemia e infecciones respiratorias bajas a repetición. Destaca haber nacido de embarazo sin complicaciones, con antropometría normal. Como antecedentes destaca estudio genético con translocación 4;8 (abuelo con la misma alteración genética, sin problemas de salud). Hermana habría fallecido a los 2 años de edad por un síndrome similar, complicada con una neumonía.

Cuenta con amplio estudio a los 4 años de edad, donde destaca laparoscopia normal y biopsia de yeyuno normal, con síntesis normal de VLDL y Fibrinógeno. Estudio absorción grasa normal, con adecuada ingesta calórico-proteica, sin diarrea. En deposiciones destaca excreción aumentada de a1- antitripsina (hasta $27 \mathrm{mg} / \mathrm{g}$ ). Sin enfermedad hepática ni proteinuria. Desde entonces con infusión mensual de inmunoglobulinas y albúmina, con lo cual resuelve transitoriamente cuadros de edema.

Exámenes pre-infusión destaca: Hemoglobina $14,6 \mathrm{~g} / \mathrm{dL}$, GB $6.500 / \mathrm{mm}^{3}$, RAN $3.850 / \mathrm{mm}^{3}$, RAL $2.040 / \mathrm{mm}^{3}$, plaquetas $151.000 / \mathrm{mm}^{3}$, albúmina $1,8 \mathrm{~g} / \mathrm{dL}$, Proteínas $3,6 \mathrm{~g} / \mathrm{dL}$, creatinina plasmática $0,6 \mathrm{mg} / \mathrm{dL}$, nitrógeno ureico $13 \mathrm{mg} / \mathrm{dL}$, INR 1,2 , tiempo de tromboplastina activada 25 segundos, Colesterol Total $80 \mathrm{mg} / \mathrm{dL}$, HDL $24 \mathrm{mg} / \mathrm{dL}$, LDL $50 \mathrm{mg} / \mathrm{dL}$, Triglicéridos $29 \mathrm{mg} / \mathrm{dL}$, Ferritina $28 \mathrm{ng} /$ $\mathrm{mL}$, ceruloplasmina $15,6 \mathrm{mg} / \mathrm{dL}$, niveles vitamina D $6 \mathrm{ng} / \mathrm{mL}$, niveles vitamina B12 $250 \mathrm{pg} / \mathrm{mL}$. Fue derivada para reevaluación diagnóstica y manejo. Se realizó estudio endoscópico descrito normal y una colonoscopia, cuya ileoscopia demostró los siguientes hallazgos (Figura $1 \mathrm{~A}-\mathrm{C}$ ).
'Departamento de Gastroenterología, Escuela de Medicina, Pontificia Universidad Católica de Chile. Santiago, Chile. ${ }^{2}$ Departamento de Medicina Interna, Escuela de Medicina, Pontificia Universidad Católica de Chile. Santiago, Chile.

Recibido:

Aceptado:

Correspondencia a: Dr. Manuel Álvarez Lobos

Departamento de Gastroenterología Pontificia Universidad Católica de Chile. Santiago, Chile. manalvarezl@gmail. com

¿Cuál es su diagnóstico? 


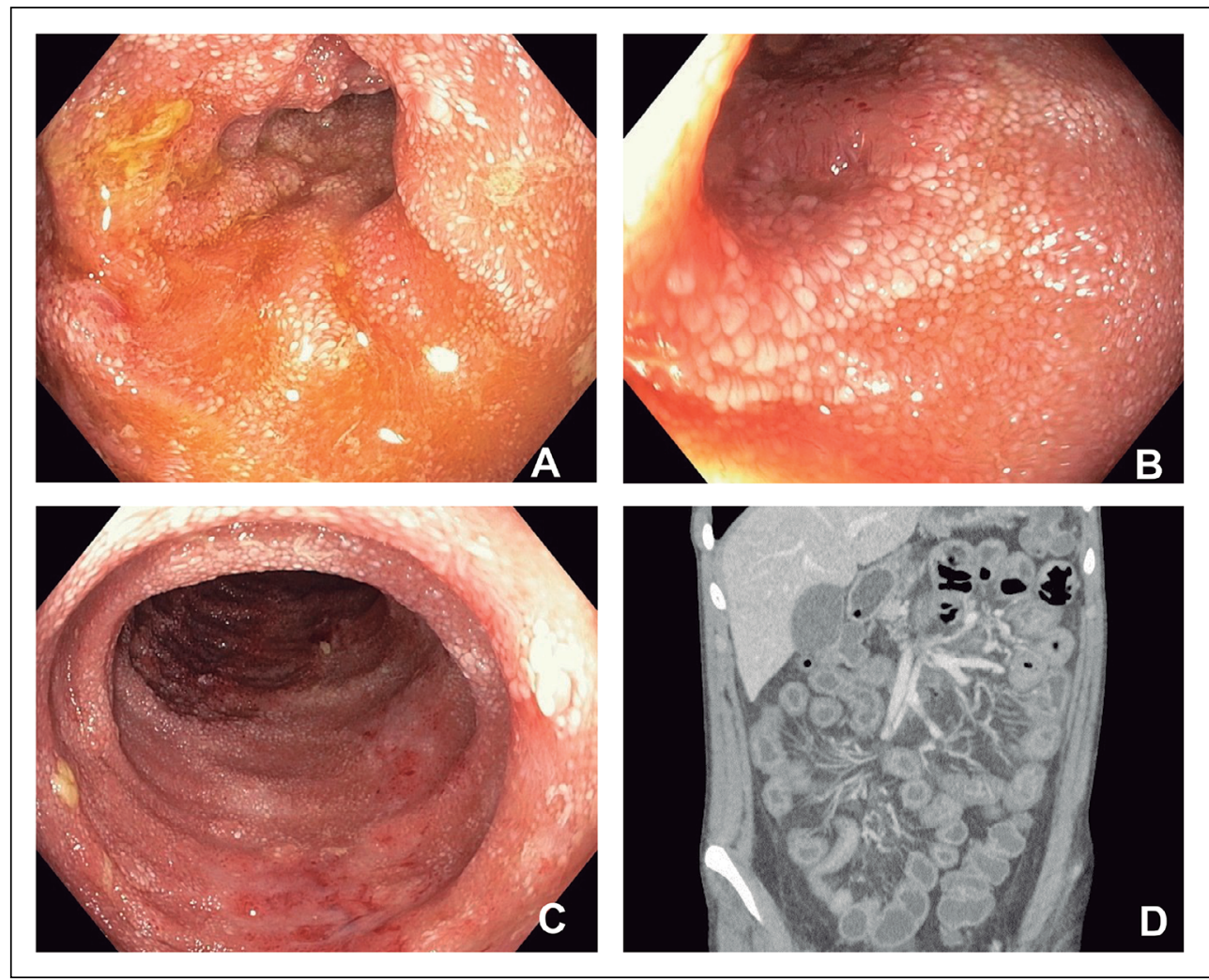

Figura 1.- Láminas A-C: Mucosa de íleon terminal con aspecto edematoso, dilatación de vellosidades blanquecinas; destacan algunas zonas con pérdida de vellosidades. Lámina D: tomografía computada (TC) de abdomen y pelvis (coronal) donde se observa engrosamiento parietal difuso de asas de intestino delgado desde el ángulo de Treitz hasta la válvula ileocecal que se manifiesta con una morfología "en diana", con edema submucoso e hiperemia mucosa moderada.

Las imágenes de íleon demuestran una mucosa edematosa de forma difusa, con vellosidades alargadas y blanquecinas, lo cual fue evidente a lo largo de los últimos $20 \mathrm{~cm}$ de íleon explorados, sugerentes de linfangiectasia. La biopsia demostró dilatación de los conductos linfáticos en las vellosidades, compatible con una linfangiectasia intestinal ${ }^{1}$. Adicionalmente, se dispone de tomografía computada de abdomen y pelvis que evidencia engrosamiento parietal difuso de asas de intestino delgado desde el ángulo de Treitz hasta la válvula ileocecal, realizada de forma cercana al momento de la colonoscopia (Figura 1D).

El caso previamente expuesto fue enfrentado inicialmente de forma sindromática como enteropatía perdedora de proteínas (EPP). En este escenario podemos observar frecuentemente edema generalizado, síntomas gastrointestinales (dolor, diarrea, anorexia, entre otros) y disnea (secundario a derrame pleural o pericárdico $)^{2}$. Fisiopatológicamente se describen tres posibles mecanismos: aumento de permeabilidad intestinal (como en la Enfermedad celíaca, Enferme- dad de Ménétrier, etc.), inflamación exudativa (como en Enfermedad de Crohn, Enfermedad injerto versus huésped, etc.) y la obstrucción linfática (linfangiectasia primaria o secundaria) $)^{3}$. En la medida en que contamos con mejores herramientas diagnósticas, ha disminuido de forma importante el enfrentamiento sindromático como EPP, ya que podemos identificar de forma mucho más rápida y específica la patología intestinal (especialmente en el estudio de intestino delgado).

Nuestra impresión diagnóstica corresponde a una linfangiectasia intestinal primaria, pues cuenta con un amplio estudio previo que descartó insuficiencia cardíaca, pericarditis, síndrome linfo-proliferativo, fibrosis retroperitoneal, entre otras causas secundarias.

Aunque la linfangiectasia es un hallazgo frecuente en las endoscopias digestivas altas (hasta un 3\% de las endoscopias diagnósticas), la gran mayoría de los pacientes no tiene síntomas gastrointestinales asociados $^{4}$. Aparte de los síntomas descritos en la EPP, los pacientes con linfangiectasia pueden presentar 
disminución de vitaminas liposolubles y linfopenia. La linfangiectasia primaria es una patología rara, con menos de 200 casos publicados a la fecha ${ }^{5}$. Se ha identificado una edad promedio al diagnóstico de 12 años, con 56,2\% de varones. Más del 90\% de los casos de linfangiectasia primaria son esporádicos ${ }^{6,7}$. El compromiso intestinal es habitualmente difuso, por lo que siempre debemos descartar un linfoma en aquellos pacientes con compromiso localizado ${ }^{4}$.

Los tratamientos descritos incluyen el soporte oncótico e inmunológico, manejo nutricional, análogos de la somatostatina y la cirugía. Respecto al soporte, se puede utilizar infusiones de albúmina e inmunoglobulinas para disminuir edema y riesgo de infecciones, respectivamente. En cuanto al manejo nutricional, se recomienda reemplazar los ácidos grasos de cadena larga por ácidos grasos de cadena media (ya que estos últimos se absorben vía circulación portal) y proteínas 1,5-3 g por kilo de peso ideal. Se ha descrito el uso de octreotide en algunos pacientes, con mejoría principalmente del edema y la hipoalbuminemia ${ }^{7}$. Respecto a la cirugía, ésta se debe plantear primordialmente en pacientes con compromiso intestinal localizado. Finalmente, cabe destacar que estos pacientes presentan un alto riesgo de infecciones bacterianas a lo largo de la vida, y en una serie, el 5\% de los pacientes desarrolló linfoma a largo plazo (promedio 31 años desde el diagnóstico) $)^{5}$.

\section{Referencias}

1.- Borzutzky A, Espino A, Alberti G, Torres J, Harris PR. Primary Intestinal Lymphangiectasia (Waldmann's Disease). Am J Gastroenterol. 2019;114:197.

2.- Umar SB, DiBaise JK. Protein-losing enteropathy: case illustrations and clinical review. Am J Gastroenterol. 2010;105:43-9; quiz 50.

3.- Levitt DG, Levitt MD. Protein losing enteropathy: comprehensive review of the mechanistic association with clinical and subclinical disease states. Clin Exp Gastroenterol. 2017;10: 147-68.

4.- Tominaga K, Tsuchiya A, Mizuno KI, Terai S. Duodenal lymphangiectasia distinguished from follicular lymphoma by narrow-band imaging magnification endoscopy. Gastrointestinal endoscopy. 2019;90:528-9.

5.- Wen J, Tang Q, Wu J, Wang Y, Cai W. Primary intestinal lymphangiectasia: four case reports and a review of the literature. Dig Dis Sci. 2010;55:3466-72.
6.- Prasad D, Srivastava A, Tambe A, Yachha SK, Sarma MS, Poddar U. Clinical Profile, Response to Therapy, and Outcome of Children with Primary Intestinal Lymphangiectasia. Digestive diseases (Basel, Switzerland). 2019;37:458-66.

7.- Alshikho MJ, Talas JM, Noureldine SI, Zazou S, Addas A, Kurabi H, et al. Intestinal Lymphangiectasia: Insights on Management and Literature Review. Am J Case Rep. 2016;17:512-22. 